\title{
Process simulation and sensitivity analysis of waste plastics gasification in a fluidized bed reactor
}

\author{
P. Kannan, A. Al Shoaibi \& C. Srinivasakannan \\ Department of Chemical Engineering, The Petroleum Institute, \\ Abu Dhabi, UAE
}

\begin{abstract}
This paper presents a simplified process simulation model of typical waste polyethylene gasification in a fluidized bed reactor using Aspen Plus. The proposed model incorporates both physical and chemical processes, including drying, pyrolysis, combustion and gasification, by using various inbuilt modules to predict the resulting product gas composition and temperature. A detailed sensitivity analysis investigating the effects of various process parameters, including equivalence ratio, bed height, and steam/fuel ratio has been presented. Keywords: gasification, waste LDPE, aspen plus, modelling and simulation.
\end{abstract}

\section{Introduction}

Gasification in commercial scale is practiced based on batch, semi batch and continuous modes of operation depending upon the processing capacity of the plant. Typically a plant processing large throughput utilize fluidized beds due to the advantages such as enhanced gas-solid contact, excellent mixing characteristics [1], operating flexibility [2], and ease of solids handling [3] that lead to a better overall gasification efficiency. Although there are many different types of fluidized beds available for gasification and combustion, bubbling fluidized type is the most preferred type whenever steam is used as a gasifying medium [4].

In general the process of gasification for energy extraction from solid carbon source involve three simultaneous or competing reactions namely combustion, pyrolysis and gasification. The partial combustion of solid fuel creates an oxygen devoid, high temperature condition within the reactor which promotes the 
pyrolysis reaction, breaking the fuel into products that are a mixture of char and volatiles containing small and long chain hydrocarbons. The presence of gasifying agent (air and steam) drives the water shift reaction converting the carbon sources in to a mixture of valuable chemicals, tar, fuel gases and some residual particulate matter.

In spite of numerous studies relating to extracting energy from waste, it still remains inconclusive on how the feedstock composition and the fluid bed process conditions play a role in the resulting product composition and yield. In order to exert better reliability of the system, the operating variables have to be optimized and controlled with significant accuracy. The cheapest and most effective technique to qualitatively understand the effect of each operating variable and to identify possible optimal conditions is through process simulation. Such attempts on developing simulation models for process optimization has been reported in open literature of fuel sources such as, tyre [3], coal [5-8], and biomass [4, 9-11] using various computer simulation packages. However, the utility of any process simulation tool has not been well explored or recorded in the literature for simulating plastics gasification in a fluidized bed.

The primary goal of present work is to successfully test and demonstrate the applicability of Aspen Plus to simulate the gasification process for one of the most abundantly used plastic, polyethylene (PE). The simulation aims to provide preliminary qualitative and quantitative information on the overall behavior of the gasification process including the sensitivity of process parameters. More importantly, this model was developed with the aim of supporting the design phase of the pilot plant gasifier.

\section{Model development}

\subsection{Assumptions}

The following assumptions were deliberated in the gasification model development:

- Steady state process

- Char from pyrolysis contains only carbon and ash

- Major components of the volatiles are hydrogen, $\mathrm{CO}, \mathrm{CO}_{2}$, methane, and water

- Gasification process initiates in the bed and completes in the freeboard.

\subsection{Reaction chemistry}

The gasification of polyethylene in the fluidized bed involves a series of physical and chemical processes, including drying, pyrolysis or devolatilization, oxidation, and finally char reduction. As soon as the material enters the gasifier, it is rapidly dried to remove the bounded moisture. The complex material then starts to devolatilize and yields volatile matter and residual amounts of char. The char present in the gas phase is reformed into a combustible gas mixture viz. $\mathrm{H}_{2}$, $\mathrm{CO}, \mathrm{CO}_{2}, \mathrm{CH}_{4}$, small hydrocarbons via reactions with steam, air, and carbon- 
dioxide according to the environment and kinetic mechanism. While the main reduction reactions are assumed to be initiated in the reactive zone (bed), other processes continue to occur at the freeboard region of the gasifier.

The chemical reactions depicting the char oxidation and gasification along with the kinetic parameters are shown in Table 1 . The most widely referenced kinetic data have been considered in this work.

Table 1: Gasification reactions and their kinetic parameters ( $K$ has appropriate units depending on the order of the reaction and $E$ is in $\mathrm{kJ} / \mathrm{kmol}$ ).

\begin{tabular}{|c|c|c|c|}
\hline No. & Reaction & Rate Equation & Ref \\
\hline 1 & $\mathrm{C}+\mathrm{H}_{2} \mathrm{O} \rightarrow \mathrm{CO}+\mathrm{H}_{2}$ & $2.0 \times 10^{5} \exp (-6000 / T)$ & [12] \\
\hline 2 & $\mathrm{C}+2 \mathrm{H}_{2} \rightarrow \mathrm{CH}_{4}$ & $0.12 \exp (-17921 / T)$ & [12] \\
\hline 3 & $\mathrm{CH}_{4}+\mathrm{H}_{2} \mathrm{O} \rightarrow \mathrm{CO}+3 \mathrm{H}_{2}$ & $6.1 \times 10^{14} \exp (257000 / \mathrm{RT}) \mathrm{C}_{\mathrm{CH} 4} \cdot \mathrm{C}_{\mathrm{H} 2 \mathrm{O}}$ & [5] \\
\hline 4 & $\mathrm{CO}+\mathrm{H}_{2} \mathrm{O} \rightarrow \mathrm{CO}_{2}+\mathrm{H}_{2}$ & $10^{6} \exp (-6370 / \mathrm{T})$ & [12] \\
\hline 5 & $\mathrm{CO}+3 \mathrm{H}_{2} \rightarrow \mathrm{CH}_{4}+\mathrm{H}_{2} \mathrm{O}$ & $312 \exp (30000 / \mathrm{RT}) \mathrm{C}_{\mathrm{CO}} \cdot \mathrm{C}_{\mathrm{H} 2}{ }^{3}$ & [5] \\
\hline 6 & $\mathrm{C}+\mathrm{O}_{2} \rightarrow \mathrm{CO}_{2}$ & $5.7 \times 10^{9} \exp (38200 / \mathrm{RT}) \mathrm{C}_{02}^{0.78}$ & [13] \\
\hline 7 & $\mathrm{C}+.5 \mathrm{O}_{2} \rightarrow \mathrm{CO}$ & $5.7 \times 10^{11} \exp (55000 / R T) C_{02}^{0.78}$ & [13] \\
\hline 8 & $\mathrm{C}+\mathrm{CO}_{2} \rightarrow 2 \mathrm{CO}$ & $1.6 \times 10^{12} \exp (186308 / \mathrm{RT})$ & [14] \\
\hline 9 & $\mathrm{CO}_{2}+\mathrm{H}_{2} \rightarrow \mathrm{CO}+\mathrm{H}_{2} \mathrm{O}$ & $1923 \exp (113070 / \mathrm{RT})$ & [12] \\
\hline 10 & $2 \mathrm{CO}+\mathrm{O}_{2} \rightarrow 2 \mathrm{CO}_{2}$ & $4 \times 10^{11} \exp (167269 / \mathrm{RT}) \mathrm{C}_{\mathrm{CO}} \cdot \mathrm{C}_{\mathrm{O} 2}{ }^{0.25} \cdot \mathrm{C}_{\mathrm{H} 2 \mathrm{O}}{ }^{0.5}$ & [15] \\
\hline 11 & $\mathrm{CH}_{4}+2 \mathrm{O}_{2} \rightarrow \mathrm{CO}_{2}+2 \mathrm{H}_{2} \mathrm{O}$ & $1.6 \times 10^{10} \exp (202387 / \mathrm{RT}) \mathrm{C}_{\mathrm{CH} 4}{ }^{0.7} \cdot \mathrm{C}_{\mathrm{O} 2}{ }^{0.8}$ & [15] \\
\hline 12 & $2 \mathrm{H}_{2}+\mathrm{O}_{2} \rightarrow 2 \mathrm{H}_{2} \mathrm{O}$ & $2.2 \times 10^{9} \exp (109137 / \mathrm{RT}) \mathrm{C}_{\mathrm{H} 2} \cdot \mathrm{C}_{\mathrm{O} 2}$ & [15] \\
\hline
\end{tabular}

\subsection{Aspen plus model}

The simplified process model developed in this study encompasses only the major physical (drying and separation) and chemical processes (decomposition, combustion and reduction) involved in the gasification process. Other downstream processes including syngas purification, gas concentration, and waste disposal or recirculation systems are not included in the scope of the model.

A schematic of the fluidized bed gasification process simulation developed in this study is illustrated in Figure 1. The major initial conditions of the various components of the aspen plus modules used in the development of the gasification model are summarized in Table 2. 
Table 2: $\quad$ Summary of initial values of major process parameters of various Aspen Plus modules utilized for gasification model development.

\begin{tabular}{|c|c|c|}
\hline Subprocess & Aspen Module & Input Parameters \\
\hline Drying & RSTOIC & $\begin{array}{l}\text { - } \quad \text { Temperature }=110^{\circ} \mathrm{C} \\
\text { - } \quad \text { Pressure }=1 \mathrm{~atm} \\
\text { - }\end{array}$ \\
\hline Separation & Sep & Split fraction of dried PE in outlet stream \\
\hline Pyrolysis & RYIELD & $\begin{array}{l}\text { - } \quad \text { Base case Temperature }=800^{\circ} \mathrm{C} \\
\text { - } \\
\text { - }\end{array}$ \\
\hline \multirow{2}{*}{ Gasification } & RCSTR & $\begin{array}{ll}\text { - } & \text { Heat duty }=0 \mathrm{cal} / \mathrm{s} \\
\text { - } & \text { Pressure }=1 \mathrm{~atm} \\
\text { - } & \text { Base case Reactor volume }=0.008 \mathrm{~m}^{3} \\
\text { Complete reaction set }\end{array}$ \\
\hline & RPFR & $\begin{array}{ll}\text { - } & \text { Adiabatic reactor } \\
\text { - } & \text { Pressure }=1 \mathrm{~atm} \\
\text { - } & \text { Reactor diameter }=150 \mathrm{~mm} \\
\text { - } & \text { Reactor length }=450 \mathrm{~mm} \\
& \text { Complete reaction set }\end{array}$ \\
\hline
\end{tabular}

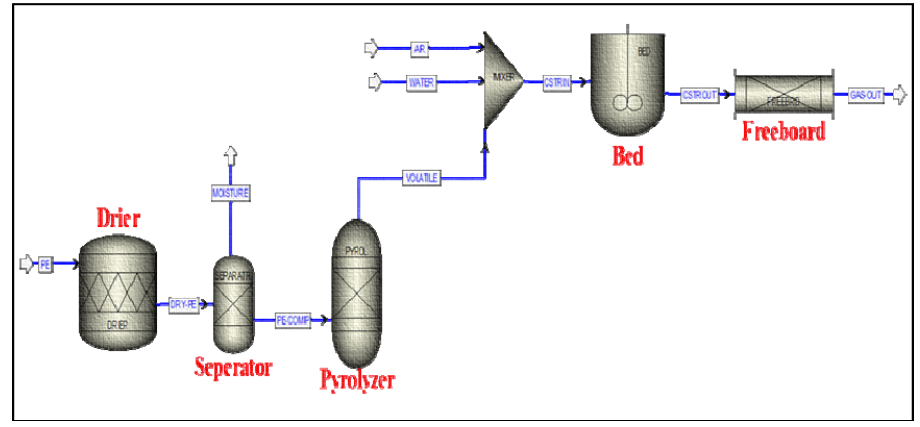

Figure 1: Aspen plus flowsheet of the fluidized bed gasification process.

\subsection{PE pyrolysis}

A yield based Aspen Plus reactor, RYIELD, was used to simulate the decomposition of the dried polyethylene sample. The complex pyrolysis of $\mathrm{PE}$ is modeled as a chemical reaction with a product stream solely consisting of PE constituent components, namely carbon, hydrogen, sulphur, nitrogen. In this module, the product yield distribution as defined by the Ultimate analysis shown in Table 3 is specified along with the process conditions of temperature, pressure, and/or heat duty. 
Table 3: $\quad$ Polyethylene sample characteristics used in this study (values taken from He et al. [16]).

\begin{tabular}{|c|c|c|c|c|c|c|c|c|c|}
\hline \multirow{2}{*}{ Sample } & \multicolumn{4}{|c|}{ Proximate Analysis (wt \%) } & \multicolumn{5}{|c|}{ Ultimate Analysis (wt \%) } \\
\cline { 2 - 10 } & Moisture & FC & Volatiles & Ash & C & H & N & Cl & S \\
\hline $\begin{array}{c}\text { Waste } \\
\text { PE }\end{array}$ & 0.02 & 0 & 99.85 & 0.15 & 85.81 & 13.86 & 0.12 & 0 & 0.06 \\
\hline
\end{tabular}

\subsection{PE gasification}

Char and volatiles resulting from pyrolysis are subjected to gasification in the bed and in the freeboard section of the gasifier. The material stream exiting from RYIELD is mixed with air and steam and transferred to the gasifying section. Using Aspen's inbuilt reactor modules RCSTR the bubbling fluidization regime in the bed was modeled as a well-mixed stirred tank reactor while the freeboard was represented as RPFR, as a plug flow reactor. In both these modules, char gasification and volatile reactions was described by reaction kinetics, as mentioned previously in this manuscript.

\section{Results and discussion}

\subsection{Effect of equivalence ratio}

Equivalence ratio (ER) is a measure of the amount of air used for gasification in relative to complete combustion. It is defined as the ratio of air/fuel ratio supplied to the stoichiometric air/fuel ratio needed for complete combustion of carbon and hydrogen present in the fuel. Altering the equivalence ratio results in significant changes in the gas phase temperature and in turn gasification efficiency. ER was varied between 0.05 and 0.25 by manipulating the air flow to the process at a fixed steam and fuel flow rate. Figure 2 illustrates the effect of ER on the product composition, exit gas temperature, and gasification efficiency

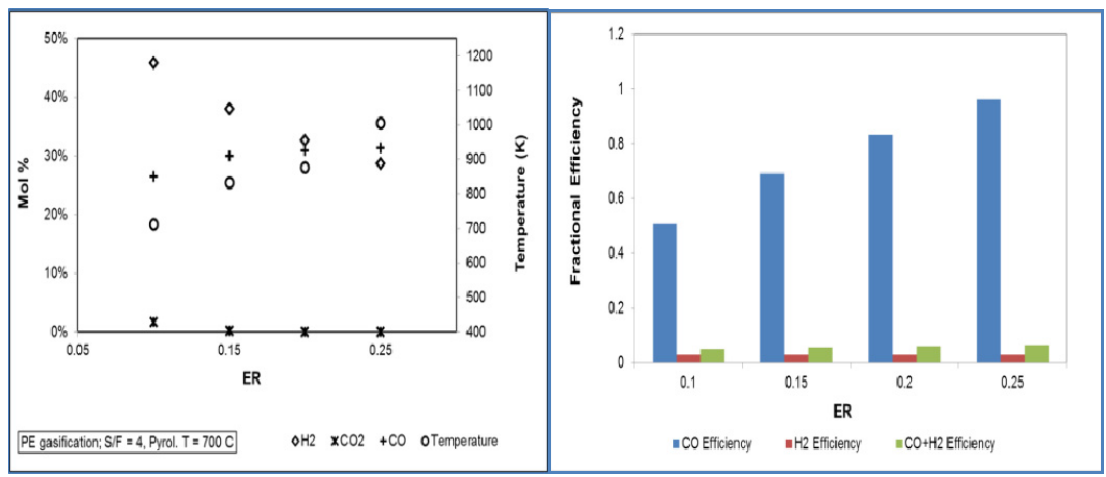

Figure 2: $\quad$ Effect of ER on gasification efficiency and product composition. 
of LDPE pyrolyzed at $700{ }^{\circ} \mathrm{C}$. As expected, an increase in ER increases product gas temperature due to the exothermic nature of combustion reactions. The product molar composition of hydrogen is a combined representation of the hydrogen actually formed in the gasification process, unreacted hydrogen from the fuel, and that dissociated from the process steam. It can be noticed that $\mathrm{CO}$ efficiency attains a maximum at an ER of 0.25 corresponding to an air flow rate of $35 \mathrm{~kg} / \mathrm{h}$. However, no significant change could be observed in hydrogen efficiency with increase in ER. This indicates that the drop in hydrogen composition is due to the corresponding increase in $\mathrm{CO}$ production due to Reaction (7) rather than the gasification reactions which otherwise would have produced significant proportion of hydrogen. Also, the composition of syngas $\left(\mathrm{CO}+\mathrm{H}_{2}\right)$ in the product stream remains unchanged beyond an ER of 0.25. Hence, the optimum ER for LDPE gasification using fluidized bed reactor is around 0.25 , beyond which the process is not viable based on both technical and economic considerations.

\subsection{Effect of steam-to-fuel ratio}

The primary role of steam in the gasification reactions is not only to enhance the yield of syngas, but also to control the selectivity of hydrogen and carbon monoxide. The effect of steam-to-PE ratio on the gasification efficiency was assessed in the range of 0.1 to 0.8 by altering the steam flow rate to the gasifier at a fixed air and fuel flow rate. Figure 3 illustrates the effect of steam on the product composition and the temperature of the product stream at a bed temperature of $700 \mathrm{C}$. It can be noticed that there is a steady drop in temperature with increasing steam content undoubtedly due to the increased participation of the endothermic gasification reactions. Both the compositional trend of $\mathrm{CO}$ and $\mathrm{H}_{2}$ shows an increase until steam-to-PE ratio is 0.5 , beyond which shows marginal decrease. The identical nature of the compositional curves of $\mathrm{CO}$ and $\mathrm{H}_{2}$ is further evidence to the domination of water gas reactions involving carbon, $\mathrm{CO}, \mathrm{CH}_{4}$ and water. Also, with increasing steam flow, higher $\mathrm{CO}$ efficiency is

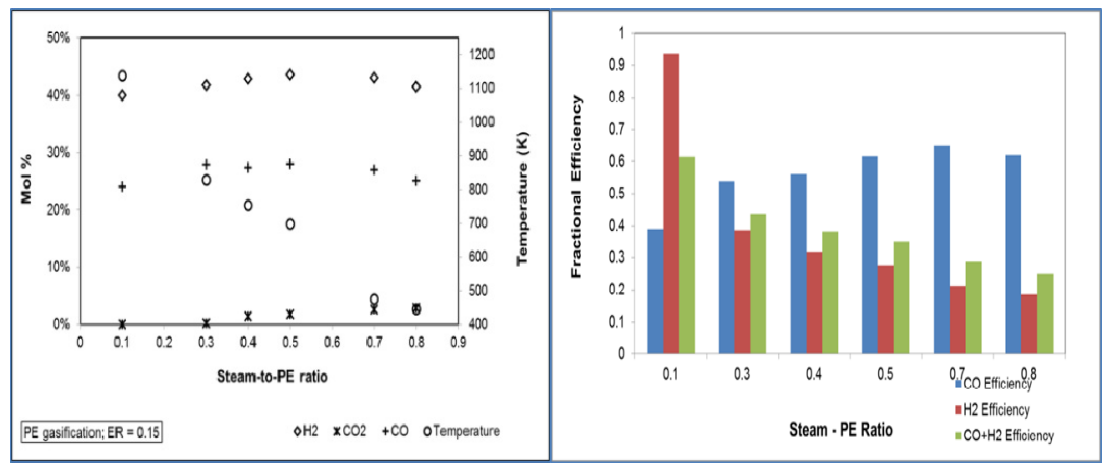

Figure 3: Effect of steam-to-fuel ratio on gasification efficiency and product composition. 
attained with a significant decrease in hydrogen efficiency. It should be noted that the reason for decrease in hydrogen efficiency (in spite of nearly constant hydrogen product composition) is related directly to the increased steam flow and by definition of hydrogen efficiency as per Equation (3). It can be concluded that an optimum range of 0.3 to 0.5 is desired, not only for maximizing the selectivity of $\mathrm{CO}$ and hydrogen, but also to have a product stream with good thermal energy suitable for practical purposes.

\subsection{Effect of bed height}

The effect of bed height on gasification efficiency was investigated in terms of the ratio of bed volume to total gasifier volume where in a value of zero corresponds to a condition of the entire gasifier considered as a freeboard (PFR) and a value of 1 would correspond to a complete bubbling bed (CSTR). The focus of this parametric analysis is to assist in design evaluation of a pilot plant gasifier. To simulate this parameter for values between 0 and 1, the bed volume (RCSTR) and freeboard volume (RPFR) were varied keeping the total volume of the gasifer as constant. For the case of bed/total volume ratio of 0 , the two reactors were replaced by a single PFR equivalent to total gasifier volume whereas for case of 1 , a RCSTR was considered with the appropriate volume. Figure 4 show the effect of bed/total volume ratio on the composition and gasification efficiency. It can be noticed that there is no significant change in product molar composition although the $\mathrm{CO}$ efficiency seem to remain highest at a complete PFR condition. Figure 5 depicts the effect of bed/total volume ratio on the feedstock conversion which was calculated from the amount of fuel fed and amount unreacted. It can be noticed that the conversion decreases with increase in bed volume or bed height since a PFR would yield better conversion than a CSTR. In reality, typically in a fluidized bed the conversion of plastic is envisaged only in the bubbling bed (CSTR) as the free board will only have the pyrolysed volatile particles, which undergo further the gas phase conversion. The fluidization velocities will be far less to facilitate a plug flow mode of the PE through the free board. A PFR mode of conversion in the fluidized bed is

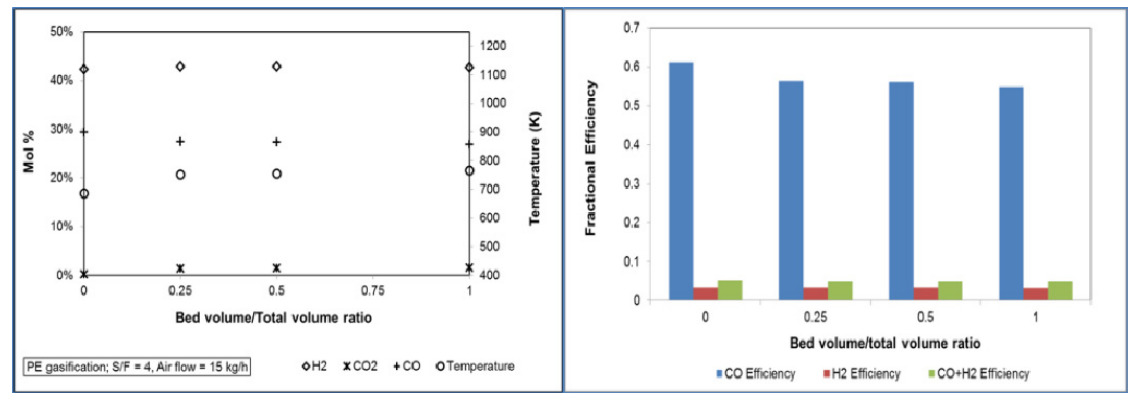

Figure 4: Effect of bed volume on gasification efficiency and product composition. 


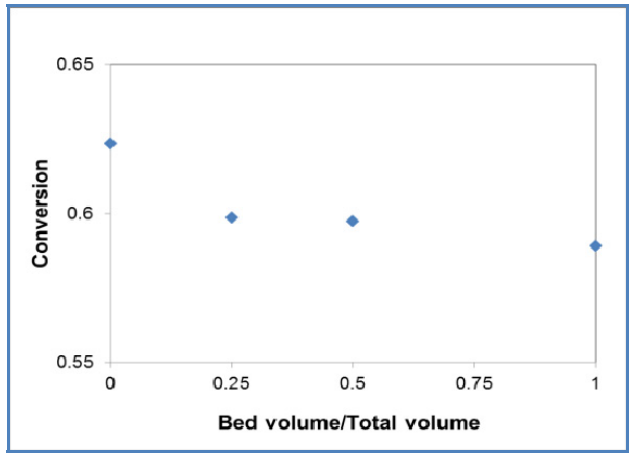

Figure 5: $\quad$ Effect of bed volume on PE conversion efficiency.

possible only at fluidization gas velocities in excess of the single particle transport velocity, which can be achieved only if the feedstock to the fluidized beds is fine powder. On the other hand operating the total volume as CSTR is not possible as distributor pressure drop should increase proportional to the bed pressure drop in order to ensure proper fluidization. In general a pressure drop of $15-20 \%$ of the bed pressure drop should be accounted for the distributor plat pressure drop in order to maintain proper fluidization.

\section{Conclusions}

An attempt was successfully made to simulate the plastics gasification process with a simplified Aspen Plus model that incorporates the significant chemical processes, namely pyrolysis, combustion and gasification using inbuilt process modules. In the course of model development, several process parameters, including equivalence ratio, steam-to-fuel ratio, and bed height were subjected to a sensitivity analysis. The following conclusions were deduced from the sensitivity analysis:

- Equivalence ratio significantly affects the product gas temperature, and in turn $\mathrm{CO}$ efficiency. An optimum value of about 0.25 is required to achieve a product gas that is rich in syngas and significant thermal energy.

- Increasing the steam content to a certain extent increases the product composition of syngas; however beyond 0.5 the selectivity drops with a significant loss in thermal energy.

- Although bed height does not have a considerable effect on the product composition or gasification efficiency, it affects feedstock conversion. With increasing bed height, the conversion was found to decrease and an optimum value in the range of 0.4 to 0.5 should be considered in order to attain reasonable conversion. 


\section{Acknowledgement}

The authors would like to extend appreciation to Borouge Plastics for supporting this project.

\section{References}

[1] Sadaka, S. S., Ghaly, A. E., and Sabbah, M. A. (2002). Two phase biomass air-steam gasification model for fluidized bed reactors: Part I--model development. Biomass and Bioenergy, 22(6), 439-462.

[2] Arena, U., Zaccariello, L., and Mastellone, M. L. (2009). Tar removal during the fluidized bed gasification of plastic waste. Waste Management, 29, 783-791.

[3] Mitta, N. R., Ferrer-Nadal, S., Lazovic, A. M., Parales, J. F., Velo, E., and Puigjaner, L. (2006). Modelling and simulation of a tyre gasification plant for synthesis gas production. In W. M. a. C. Pantelides (Ed.), Computer Aided Chemical Engineering (Vol. 21, pp. 1771-1776): Elsevier.

[4] Shen, L., Gao, Y., and Xiao, J. (2008). Simulation of hydrogen production from biomass gasification in interconnected fluidized beds. Biomass \& Bioenergy, 32(2), 120-127.

[5] Robinson, P. J., and Luyben, W. L. (2008). Simple Dynamic Gasifier Model That Runs in Aspen Dynamics. Ind. Eng. Chem. Res., 47(20), 77847792.

[6] Yan, H.-M., and Rudolph, V. (2000). Modeling a compartmented fluidized bed coal gasifier process using ASPEN PLUS. Chem. Eng. Commun., 183, $1-38$.

[7] Lee, H. G., M., C. K., Kim, C., Han, S. H., and Kim, H. T. (1992). Coal gasification simulation using Aspen Plus. Paper presented at the US - Korea Joint Workshop on Coal Gasification Technology.

[8] Douglas, P. L., and Young, B. E. (1991). Modelling and simulation of an AFBC steam heating plant using ASPEN/SP. Fuel, 70(2), 145-154.

[9] Mansaray, K. G., Al-Taweel, A. M., Ghaly, A. E., Hamdullahpur, F., and Ugursal, V. I. (2000). Mathematical modeling of a fluidized bed rice husk gasifier: part I - model development. Energy Sources, 22(1), 83-98.

[10] Nikoo, M. B., and Mahinpey, N. (2008). Simulation of biomass gasification in fluidized bed reactor using ASPEN PLUS. Biomass and Bioenergy, 32(12), 1245-1254.

[11] Doherty, W., Reynolds, A., and Kennedy, D. (2009). The effect of air preheating in a biomass CFB gasifier using ASPEN Plus simulation. Biomass \& Bioenergy, 33(9), 1158-1167.

[12] Inayat, A., Ahmad, M. M., Mutalib, M. I., and Yunus, M. K. (2009). Kinetic modelling of biomass steam gasification system for hydrogen production with $\mathrm{CO}_{2}$ adsorption. Proceedings of International conference for Technical Postgraduates, Kuala Lumpur (Malaysia).

[13] Cuoci, A., Faravelli, T., frassoldati, A., Grana, R., Pierucci, S., Ranzi, E., and Sommariva, S. (2009). Mathematical modelling of gasification and 
186 Waste Management and the Environment VI

combustion of solid fuels and wastes. Chemical Engineering Transactions, 18, 989-984.

[14] Ray, R., and Thorpe, R.B. (2007). A comparison of gasification with pyrolysis for the recycling of plastic containing wastes. International Journal of Chemical Reactor Engineering, 5, A85.

[15] Wurzenberger, J.C., Wallner, S., and Raupenstrauch, H. (2002), Thermal conversion of biomass: comprehensive reactor and particle modelling. AIChE Journal, 48 (10), 2398-2411.

[16] He, M., Xiao, B., Hu, Z., Liu, S., Guo, X., and Luo, S. (2009). Syngas production from catalytic gasification of waste polyethylene: Influence of temperature on gas yield and composition. International Journal of Hydrogen Energy, 34, 1342-1348. 